\title{
Clavien-Dindo Grade IVb
}

National Cancer Institute

\section{Source}

National Cancer Institute. Clavien-Dindo Grade IVb. NCI Thesaurus. Code C121454.

Multiorgan dysfunction. 